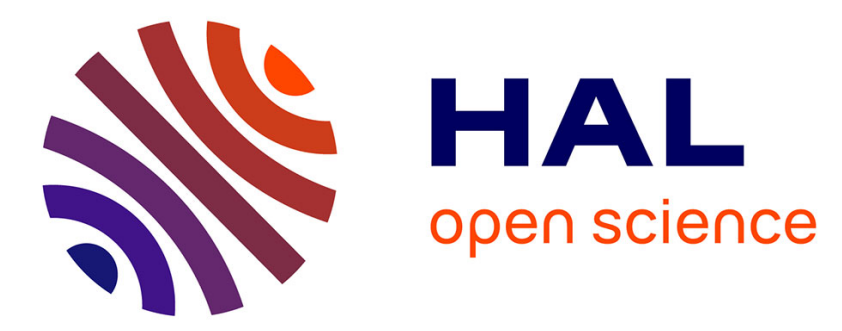

\title{
On the bandwidth enhancement of a multipolarization and reconfigurable pattern antenna for adaptive MIMO systems
}

Julien Sarrazin, Yann Mahé, Stéphane Avrillon, Serge Toutain

\section{To cite this version:}

Julien Sarrazin, Yann Mahé, Stéphane Avrillon, Serge Toutain. On the bandwidth enhancement of a multipolarization and reconfigurable pattern antenna for adaptive MIMO systems. Antenna and Propagation Symposium, Jun 2007, Hawai, United States. pp.485-488, 10.1109/APS.2007.4395536 . hal-00252019

\section{HAL Id: hal-00252019 \\ https://hal.science/hal-00252019}

Submitted on 30 Mar 2021

HAL is a multi-disciplinary open access archive for the deposit and dissemination of scientific research documents, whether they are published or not. The documents may come from teaching and research institutions in France or abroad, or from public or private research centers.
L'archive ouverte pluridisciplinaire $\mathbf{H A L}$, est destinée au dépôt et à la diffusion de documents scientifiques de niveau recherche, publiés ou non, émanant des établissements d'enseignement et de recherche français ou étrangers, des laboratoires publics ou privés. 


\title{
On the bandwidth enhancement of a multipolarization and reconfigurable pattern antenna for adaptive MIMO systems
}

\author{
J. Sarrazin ${ }^{1}$, Y. Mahé ${ }^{1}$, S. Avrillon ${ }^{2}$, and S. Toutain ${ }^{1}$ \\ ${ }^{1}$ IREENA, Université de Nantes, 44306, France \\ ${ }^{2}$ IETR, Université de Rennes I, 35042, France \\ E-mail: julien.sarrazin@univ-nantes.fr
}

\section{Introduction}

Multiple input multiple output (MIMO) systems can drastically improve wireless communication capacity and robustness by taking into account multipath effects. Nevertheless, capacity performances largely depend on the transmission channel decorrelation which is constituted by the physical propagation channel and the antennas associated to the processing circuits. Since the propagation channel is given, the antenna radiation pattern gain and polarization can be conformed to decorrelate the transmission channel and so to enhance capacity [1]. However, for non-stationary channels, antenna characteristics have to be adaptive to keep an optimal channel decorrelation [2]. So we have suggested in [3] a radiation pattern reconfigurable cubic antenna which is able to radiate in a $4 \pi$ steradians range. Furthermore, the structure produces multipolarization in order to avoid fading effects.

Wireless Local Area Networks (WLAN) applications around $5 \mathrm{GHz}$ have different frequency band channels depending on the country norm. That is why in this paper, we will investigate the bandwidth enhancement of the cubic cavity based antenna to cover all frequency bands. An enlargement from $2.5 \%$ to $12 \%$ is achieved by using the different involved resonances.

\section{Antenna structure}

The proposed antenna design is based on a metallic cube full of air as illustrated in figure 1 (a). On each face, a rectangular slot is etched which enable the antenna to radiate. The structure is fed by a probe penetrating the cube through one of its corner. The resonance frequencies of the cube can be determined by the following relation:

$$
f_{\mathbf{m n p}}=c\left[\left(\frac{m}{2 a}\right)^{2}+\left(\frac{n}{2 b}\right)^{2}+\left(\frac{p}{2 l}\right)^{2}\right]^{\frac{1}{2}}=\frac{c}{2 a} \sqrt{m^{2}+n^{2}+p^{2}}
$$

where

$$
\begin{array}{ll}
c & \text { velocity of light } \\
a, b, l & \text { rectangular cavity dimensions } \\
m, n, p & \text { modal order indexes }
\end{array}
$$

Since the cavity is cubic, its length, width and height are all equal to $a$. It should be noted that reactive slot shift down the cavity resonance frequencies. Taking this effect into account, the cube dimension $a$ is chosen to work at the first fundamental mode. Then a good impedance matching can be achieved by adjusting the probe height. 


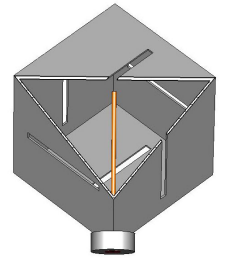

a)

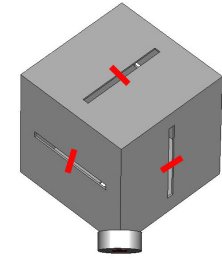

b)

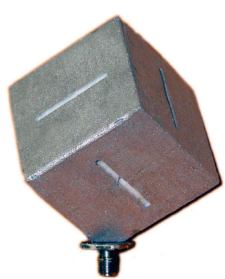

C)

Figure 1: (a) cubic antenna feeding (b) short-cutting slots and (c) built antenna.

The probe fed three orthogonal modes inside the cavity. Each adjacent slots are orthogonal to allow a coupling between them and the associated modes. Since the radiation is achieved through the orthogonal slots, multipolarization is introduced. Furthermore, by short-cutting them in their median axis, their contribution can be cancelled. So, pattern diversity can be achieved by selecting which slots are shortcutting. Three interesting configurations have been studied because of their high pattern diversity in a $4 \pi$ steradians environment. Each one contains two short-cuts on the lower sides and one on the upper side as indicated by the figure 1 (b) (the radiated slots are not visible on this figure). Switching configuration is like to rotate the cube around the monopole by 120 degrees, so, the antenna return loss is not affected by the change of configuration.

Realizations have been done and an exemple is given on figure 1 (c). Antennas are built with foam substrate which has a permittivity near vaccum's $(\epsilon=1,02)$. The cube foam is coated with a silver painting. Slots are milled after. A hole is drilled to allow the probe insertion in the foam cavity. Short-cuts are made by a simple way with an one millimeter width metal-coated scotch-tape for now but an electronically switches based antenna will be investigated in a further paper.

\section{Bandwidth enhancement}

A first example of the presented antenna was designed. As previously seen, cube frequency resonances are linked to its dimensions and also to the reactive impedance of each slot. Without slots, the cube side size is about $w c=40.4 \mathrm{~mm}$ to resonate at $5.25 \mathrm{GHz}$. When slots are etched, the bigger they are, the lower the resonance frequency is. So a correction on the cube dimensions is necessary. To keep the 5.25 $\mathrm{GHz}$ frequency, the cube size is $w c=39.2 \mathrm{~mm}$ for a slot length $l s=24 \mathrm{~mm}$ and a slot width $w=2 \mathrm{~mm}$. The simulated return loss is shown on figure 2 . The $-10 \mathrm{~dB}$ bandwidth is about $2.5 \%$ which is too narrow to cover the whole WLAN frequency band. In order to increase it, a solution is to take advantage of the multiresonant behavior of the structure. In fact, in addition to the cavity resonances, slots get also their own resonances. By a judicious design, it is possible to overlay the two resonances involved. With the dimensions $w c=30.3 \mathrm{~mm}, l \mathrm{~s}=28.6 \mathrm{~mm}$ and $w=2 \mathrm{~mm}$, slots and cavity resonances are around $5.25 \mathrm{GHz}$. So, a bandwidth enhancement from $2.5 \%$ to $6.1 \%$ is achieved. The simulation return loss is presented on the figure 2. However, shifting the two resonance poles can leed to a further 
enlargement of the bandwidth. So a third antenna was designed with $w c=38 \mathrm{~mm}$, $l s=27 \mathrm{~mm}$ and $w=2 \mathrm{~mm}$. Simulation results are shown on the figure 2 . Thus, the slot resonates at $5.5 \mathrm{GHz}$ whereas the cubic cavity at $5.15 \mathrm{GHz}$. Then the frequency bandwidth is increased up to $12 \%$.

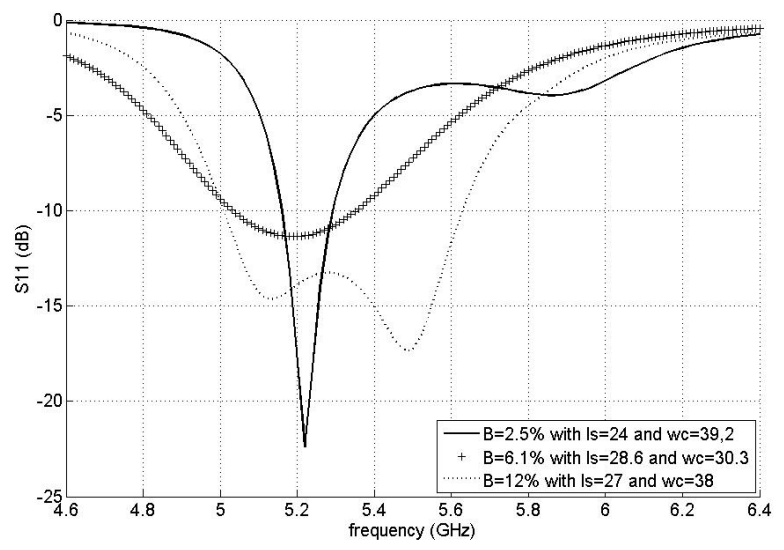

Figure 2: Return loss for three different cube sizes.

\section{Radiation antenna performance}

Simulated radiation patterns of the antenna short-cut as shown on figure 3 are provided on figure 4 and 5. Only one short-cut configuration is given because the two others lead to the same radiation results with a rotation of 120 degrees. Patterns are drawn along spherical coordinates $\theta$ and $\phi$. The gain $\theta$ is defined using the electric field projection on the vector $u_{\theta}$ and the gain $\phi$ using the projection on the vector $u_{\phi}$. On the figure 4 , the $2.5 \%$ frequency bandwidth antenna pattern is presented. The structure radiates in a $4 \pi$ steradians range with some maximum gain directions. Depending on the configuration, the radiated slots are not the same and accordingly, maximum gain directions change. Hence pattern diversity is achieved between each configuration. Maximum gain values along $\theta$ and $\phi$ are both approximately equal to $3 \mathrm{~dB}$ which confirms the multipolarization effect. Figure 5 shows the $12 \%$ bandwidth antenna radiation patterns for both frequencies $5.13 \mathrm{GHz}$ and $5.48 \mathrm{GHz}$. It is worth interesting to note that the radiation pattern shape is constant over the whole bandwidth on the $4 \pi$ steradians range. Moreover, the bandwidth enhancement did not disturbed the radiation shape already obtained with the $2.5 \%$ bandwidth antenna.

\section{Conclusions}

A multipolarization cubic antenna concept which introduces pattern diversity for adaptive MIMO systems has been presented. The frequency bandwidth has been improved keeping radiation characteristics constant over the whole band. 


\section{References}

[1] M.A.Jensen, J.W.Wallace, "A review of antennas and propagation for MIMO wireless communications", IEEE Trans. Antennas Propagat., vol. 52, pp. 28102824, november 2004

[2] B.A.Cetiner, E.Akay, E.Sengul, E.Ayanoglu, "A MIMO system with multifunctional reconfigurable antennas", IEEE Antennas and Wireless Propagation Letters., vol. 5, pp. 463-466, 2006

[3] J.Sarrazin, Y.Mahe, S.Avrillon, S.Toutain, "Multibeam and orthogonal polarization antenna", EUCAP 2006, Nice, France, november 2006

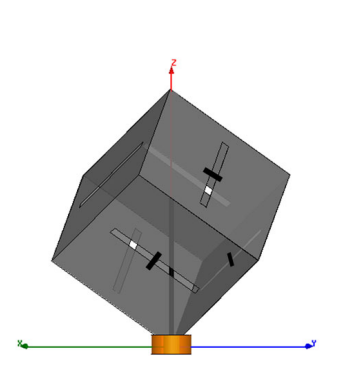

Figure 3: Short-cut cube.
Gain Theta

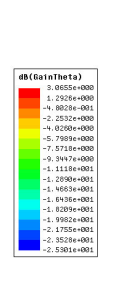

Gain Phi

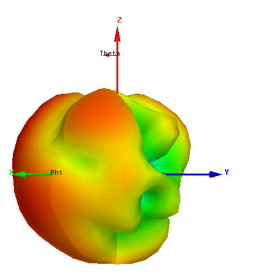

$$
\mathrm{f}=5.25 \mathrm{GHz}
$$

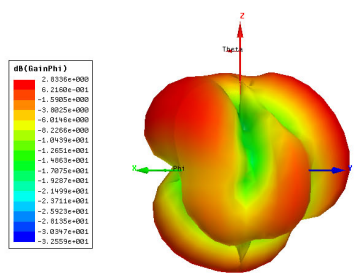

Figure 4: Gain $\theta$ and gain $\phi$ at $5.25 \mathrm{GHz}$.

Gain Theta
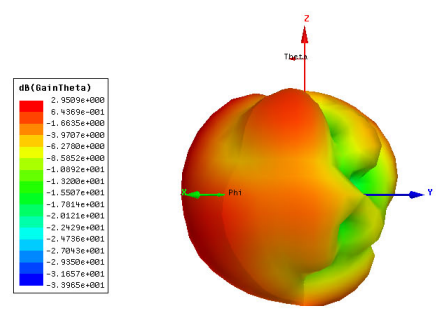

$\mathrm{f}=5.13$

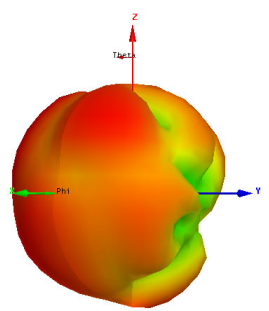

Gain Phi

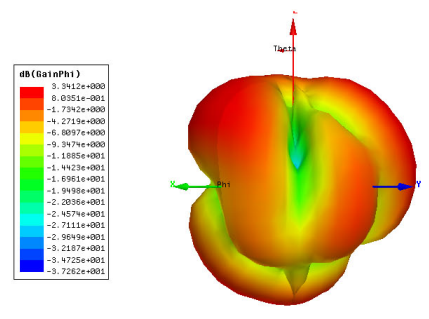

$\mathrm{GHz}$
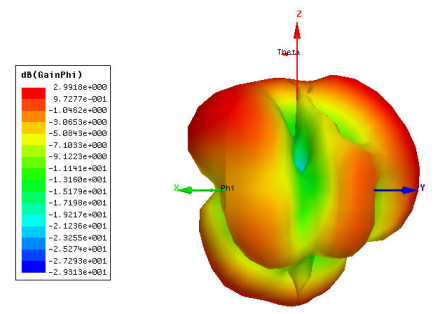

$$
\mathrm{f}=5.48 \mathrm{GHz}
$$

Figure 5: Gain $\theta$ and gain $\phi$ at $5.13 \mathrm{GHz}$ and $5.48 \mathrm{GHz}$. 